\title{
Near-Global Survey of Cloud Column Susceptibilities Using ISCCP Data
}

Qingyuan Han ${ }^{1}$, William. B. Rossow ${ }^{2}$, Joyce, Chou ${ }^{1}$, and Ronald M. Welch ${ }^{1}$

${ }^{1}$ Department of Atmospheric Science

University of Alabama in Huntsville

${ }^{2}$ Goddard Institute for Space Studies, NASA 


\begin{abstract}
A new parameter, cloud column susceptibility, is introduced to study the aerosol indirect effect. There are several advantages of this new parameter in comparison with the traditional cloud susceptibility. First, no assumptions about constant liquid water content and cloud layer thickness are required in calculations so that errors caused by these assumptions can be avoided. Second, no a priori knowledge of liquid water content is necessary in remote sensing, which makes global survey by satellite data possible even though liquid water content may change significantly. Third, this new parameter can deal with variations of cloud geometrical thickness during cloud-aerosol interactions, which are evidenced by sbservations. Without assuming how cloud droplet size will respond to changes of number concentration, this new parameter describes the aerosol indirect effect more directly. It addresses the question of how cloud albedo changes with increasing column number concentrations of cloud droplets, which is resulted from cloud-aerosol interactions. In this study, two approaches are used to retrieve cloud column susceptibility by satellite dati. The results of both approaches show a striking contrast of cloud column susceptibilities between continental and maritime. Between the two approaches, the one that uses no assumption of constant liquid water content leads to smaller, some times even negative, cloud column susceptibilities. This finding suggests that the aerosol indirect effect may be overestimated if the assumption of constant liquid water content is used in model studies.
\end{abstract}




\section{Introduction}

Among possible radiative forcings that can cause long-term climate change, the effect of changing tropospheric aerosols on cloud properties (called the aerosol indirect effect) is the most uncertain $\left(0\right.$ to $\left.-1.5 \mathrm{Wm}^{-2}\right)$ relative to the other known forcings, and which is the only one without even a mid-range estimate (IPCC, 1996). Recent model study further suggests that the indirect aerosol effect may be playing vital role in global change (Hansen et al., 1997).

One approach to estimate the aerosol indirect effect is to evaluate the cloud albedo change due to variations of aerosol loading. Twomey (1991) first introduced the concept of cloud susceptibility, defined as cl'sud albedo change versus number concentration change of cloud droplets, $\mathrm{d} \alpha / \mathrm{dN}$, which is a valuable parameter that indicates where clouds are more susceptible to the cloud-aerosol interact:on. However, the accuracy of calculation and feasibility of remote sensing of this parameter have been limited by the assumption used in the calculation and certain information required in the remote sensing (liquid water content). Traditionally, the calculation of cloud susceptibility is based on assumptions of constant liquid water content and cloud geometrical thickness (Platnick and Twomey, 1994, Taylor and Mchaffie, 1994). These assumptions are often violated even for non-precipitating clouds. Because a balance between condensation and evaporation is difficult to maintain since they depend on supersaturation (and thus vertical velocity), humidity of the ambient air far from the droplet, diffusion coefficient, and cloud droplet size. In reality, during the cloud-aerosol interactions these factors are always changing. Observations show different cases where liquid water content increases (e.g., Radke et al., 1989), decreases (e.g. Fitzgerald and Spyers-Duran 1973), or approximately holds constant (e.g., Leaitch et al. 1992). For more detailed discussion on this issue, readers are suggested to read Han et al. (1998a) and the references therein. There are also observational evidences showing that cloud geometrical thickness increases when aerosols were activated to form cloud droplets (e.g., Hobbs et al. 1970).

Another problem that makes the remote sensing of the cloud susceptibility on a global scale difficult is the fact that a priori knowledge of liquid water content is required. In the 
pioneer study of remote sensing of cloud susceptibility (Platnick and Twomey, 1994), the equation used is in the form

$$
\frac{d \alpha}{d N} \approx \frac{\partial \alpha}{\partial \tau} \frac{d \tau}{d N} \approx \frac{\partial \alpha}{\partial \tau} \frac{\tau}{3 N}=\frac{4 \pi \rho_{w}}{9 w} \alpha(1-\alpha) r_{v}^{3} ; \alpha \approx \frac{(1-g) \tau}{2+(1-g) \tau}
$$

where $w$ represents the cloud liquid water content. Although the effective radius, $\mathrm{r}_{\mathrm{e}}$, and optical thickness, $\tau$, can be retrieved form satellite, values of liquid water content has to be known in order to retrieve the cloud susceptibility. In the study of Platnick and Twomey, $g \approx 0.85, r_{v}=r_{e}$, $w=0.3 \mathrm{~g} / \mathrm{m}^{3}$ were assumed. This approach is valid for case studies when the liquid water content can be obtained by other measurements. However, in general, liquid water content depends on entrainment and saturated adiabatic values that vary strongly from cloud to cloud. The values of liquid water content range from $0.2 \mathrm{~g} / \mathrm{m}^{3}$ ip to $5 \mathrm{~g} / \mathrm{m}^{3}$ (e.g., Pruppacher and Klett, 1997, p23), which may cause the resultant uncertainty in clo id susceptibility more than one order of magnitude if global survey of this parameter is conducted.

In addressing the important issue of the aerosol indirect effect, we used ISCCP data to estimate cloud-aerosol interactions on a near-global scale. Since the difficulties in calculating and remote sensing of the parameter of cloud susceptibility, we developed a new parameter, cloud column susceptibility. This new parameter has several advantages. First, it can be easily used in model calculations without the assumption of constant liquid water content. Second, it can be retrieved globally using satellite data without the assumption of an average value of liquid water content. Third, this new parameter has already included the effect of possible variations of cloud geometrical thickness during cloud-aerosol interactions, which are reported from observations (e.g., Hobbs et al., 1970). Traditional way of estimating the indirect aerosol effect is to evaluate droplet size change due to changes in number concentration of cloud droplets under the assumption of constant liquid water path. However, this approach may introduce errors when cloud liquid water content is not constant, as evidenced by many observations. This new parameter describes the indirect aerosol effect more directly without assuming how cloud droplet size will respond to changes of number concentration. To be more specific, the cloud column susceptibility describes 
how cloud albedo changes with increasing column number concentrations of cloud droplets, which is resulted from cloud-aerosol interactions.

The cloud column susceptibility is retrieved using two approaches, i.e., with and without the assumption of constant liquid water content in order to evaluate the difference and to compare with results of other investigations.

\section{Method}

The cloud column susceptibility is defined by

$$
S_{c}=d o / d N_{c}
$$

where $\alpha$ is cloud spherical albedo and $N_{c}$ is cloud column droplet concentration. The column droplet concentration is defined by

$$
N_{c}=I ! \cdot h
$$

The retrieval method of $N_{c}$, validation effort, and rest.lts of a global-survey have been described by Han et al. (1998b). The global distribution of $N_{c}$ sh $\nu$ w the expected increase of column droplet concentrations between ocean and continental clouds and in tropical areas during dry seasons where biomass burning is prevalent. It is demonstrated that column droplet concentration is a good indication of available $\mathrm{CCN}$ populations in certain areas.

Two approaches are used to retrieve cloud column susceptibility. One approach uses the assumption of constant liquid water content and the other approach does not. In both approaches, cloud optical thickness and effective droplet radius are retrieved using the three-channel method (Han et . al. 1994). We retrieve cloud optical thickness ( $\tau$ ) and effective droplet radius $\left(r_{e}\right)$ from satellite-measured radiances at $0.63,3.7$ and $10.7 \mu \mathrm{m}$ wavelength (channels 1,3 and 4 of AVHRR on NOAA polar orbiting satellites). This is performed by comparison with calculations from a radiative transfer model that represents the spectral and angle dependence of radiation, accounting for multiple scattering by gases and clouds and for other atmospheric and surface effects. The analysis is applied to pixel-level data (stage CX data) from the International Satellite Cloud Climatology Project (ISCCP, Rossow and Schiffer, 1991) which identifics cloudy satellite pixels. 
Liquid water clouds are identified by channel 4 brightness temperatures $>273 \mathrm{~K}$, implying cloud tops below the freezing level. Individual pixels are about $5 \mathrm{~km}$ across and have been sampled at intervals of about $30 \mathrm{~km}$. Since cloud scattering at $0.63 \mu \mathrm{m}$ is conservative, $\tau$ values represent the whole cloud layer. However, most of the signal at $3.7 \mu \mathrm{m}$ used to determine $r_{e}$ comes from the uppermost portion of the cloud (Han et al., 1994).

\subsection{Approach One: Assuming constant liquid water content}

Under the assumption of constant water content, we have

$$
\frac{d \tau}{d N_{c}}=\frac{\tau}{3 N_{c}}
$$

and thus the column cloud susceptibility is

$$
S_{c}=\frac{d \alpha}{d N_{c}} \approx \frac{\partial \alpha}{\partial \tau} \frac{d \tau}{d N_{c}} \approx \frac{\partial \alpha}{\partial \tau} \frac{\tau}{3 N_{c}}=\frac{\alpha(i-\alpha)}{: N_{c}}
$$

The column droplet concentration, $N_{c}$, and the spherical albedo of clond, $\alpha$, are retrieved from satellite radiance data (Han et al., 1998a, b). Based on these retrievals, the column susceptibility can be derived for each cloud pixels. This approach is similar to the one used by Platnick and Twomey (1994) in retrieving cloud susceptibility. The major difference is that the parameter

retrieved here is cloud column susceptibility in which no assumption about the value of liquid water content is required. Hence, it can be applied in any region no matter what the value of cloud liquid water content might be.

This approach is actually answering the following question: giving the current cloud properties, if cloud liquid water content will not change during cloud-aerosol interactions, what would be the cloud column susceptibility. Apparently, the calculated (or predicted) cloud column susceptibility will be incorrect if the assumption of constant liquid water content is invalid, which is the case from many observations. In essential, the assumption of constant liquid water content is a constraint about the droplet size change in response to the change of number concentration due to cloudaerosol interactions. Under this assumption, the response is equivalent to, 


$$
\frac{d r_{e}}{d N}=-\frac{r_{e}}{3 N}
$$

In reality, cloud liquid water content has been observed to increase, decrease or maintain constant and thus the responses can be quite different. Different behaviors of liquid water content lead to different results of cloud susceptibility. To determine these behaviors for a specific cloud pixel from satellite data is very difficult, if not impossible. Therefore, we used the regression method as the second approach in which the tendency of changes in cloud liquid water is implicitly determined by all cloud pixels in a grid box.

\subsection{Approach Two: Regression Method}

Under this approach, no assumption about liquid water content is made and biases caused by this assumption are eliminated. The column susceptibility

$$
S_{c}=\frac{d \alpha}{d N_{c}} \approx \frac{\Delta \alpha}{\Delta N_{c}}
$$

is derived from statistical regression with $N_{c}$ and $\alpha$ retrieved from satellite radisance data (Han et al., 1998a). The column susceptibility values of each $2.5^{\circ} \times 2.5^{\circ}$ grid box are derived from a linear regression of all water cloud pixels (determined by cloud top temperature $>273 \mathrm{~K}$ ) within this grid box during one month. Typical pixel numbers are $>100$ for each grid box. If pixel number in a grid box is less than 10 , no regression is conducted and the grid box is left blank.

This approach does not assume the behavior of cloud liquid water. Instead, it uses regression technique to find the value of cloud column susceptibility that is a result of dominant behavior of cloud liquid water in a grid box within the period of one month.

\section{Results}

Figures land Fig. 2 are the retrieved column susceptibility for thin $(\tau \leq 15)$ clouds by the first and the second approaches, respectively. Figures 1 and 2 both show the striking contrast of cloud column susceptibilities between continental and maritime clouds. For clouds over most of continents, the column cloud susceptibility is around zero or slightly positive $\left(\leq 1.8 \times 10^{-8} \mathrm{~cm}^{2}\right)$, 
suggesting little cloud albedo change due to the cloud column droplet concentration change. For most oceanic clouds, the column susceptibilities are high, suggesting a large albedo increase due to an increase in the column droplet concentration. Under clean oceanic environment, for a typical maritime cloud with $300 \mathrm{~m}$ physical thickness, the column cloud susceptibility of $6.6 \times 10^{-8} \mathrm{~cm}^{2}$ means that an increase in volume cloud droplet concentration of $10 \mathrm{~cm}^{-3}$ would increase cloud albedo by $2.0 \%$. This is plausible due to the volume cloud droplet concentration of a typical marine cloud is only about $40 \mathrm{~cm}^{-3}$.

Case studies of cloud susceptibility from California and Namibia regions were reported by Platnick and Twomey (1994) and Taylor and McHaffie (1994). The results of Platnick and Twomey, using AVHRR at $\sim 15 \mathrm{~km}$ resolution for ship-track region in stratocumulus we:t of Washington State on March 2, 1990, are used here for comparison because detailed informatic $n$ of cloud properties are included. All the twenty-eight retrieved results of cloud susceptibilities are converted to cloud column susceptibilities by the liquid water path and liquid water cor tent reported in their studies. The converted cloud column susceptibility of these 28 cases is 10.6:-29.6 $\times 10^{-8} \mathrm{~cm}^{2}$. The value will be $21.5 \pm 8.5 \times 10^{-8}$ if only out-of-track regions (10 cases) are considered and $4.6 \pm 1.3 \times 10^{-8} \mathrm{~cm}^{2}$ if only in-track regions ( 18 cases) are included. The total averaged value is in good agreement with the results of west of Washington State in April $1987\left(10-12 \times 10^{-8} \mathrm{~cm}^{2}\right)$ if constant liquid water content is assumed (Fig. 1). Note that their results are based on an average liquid water content value of $0.3 \mathrm{~g} / \mathrm{m}^{2}$ in retrievals and this comparison shows that this assumed value is representative in that region and season. Another data used for comparison is from observations in marine stratocumulus clcuds at the west coast of southern California in the vicinity of $32^{\circ} \mathrm{N}$ and $120^{\circ} \mathrm{W}$ in July 1987 (Radke et al., 1989). According to the cloud properties supplied in the paper $\left(\mathrm{r}_{\mathrm{e}}=10-12 \mu \mathrm{m}, \mathrm{w}=0.3-0.4 \mathrm{~g} / \mathrm{m}^{3}, \Delta \mathrm{z}=500 \mathrm{~m}\right.$ ) and using equation (1), the range of the converted cloud column susceptibility is from $1.5 \times 10^{-8} \mathrm{~cm}^{2}$ to $3.9 \times 10^{-8} \mathrm{~cm}^{2}$. This agrees well with the value of $2.0 \times 10^{-8}$ to $4.0 \times 10^{-8} \mathrm{~cm}^{2}$ from Fig. 1 for July 1987 at the west coast of Califomia.

The main difference between results from Figs. 1 and 2 is that the column susceptibility is smaller if no constant water content is assumed in the retrieval. The reason will be discussed 
later. This difference is more significant over continents and surrounding ocean areas. For example, in July, at the West Atlantic, the average cloud column susceptibility drops from about $9.0 \times 10^{-8} \mathrm{~cm}^{2}$ (assuming constant liquid water content) to about $1.6 \times 10^{-8} \mathrm{~cm}^{2}$ (no assumption about liquid water content). This may be caused by the air pollution from the East Coast of the United States.

The major difficulty in understanding the statistically regressed susceptibility is the negative values because the derivative $d r / d N_{c}$ is thought to be positive in all cases, which is actually only valid if one keeps the liquid water content constant. To be more specific, an increase of cloud droplet number may lead to two consequences: increasing cloud optical thickness and decreasing cloud droplet size. The decrease of cloud droplet size may be thought to cause an increase of cloud optical thickness because

$$
\tau=\pi \int_{0}^{h} \int_{0}^{\infty} Q_{e x t} r^{2} n(r) d r d h^{\prime}=Q_{c x t} \frac{\pi \bar{r}^{3} N}{r_{e}} h \approx \frac{3}{2} \frac{w}{r_{e}} h
$$

where $\bar{r}$ is the volume average droplet radius and $N=\int_{0}^{\infty} n(r) d r$ is the total number concentration of cloud droplets. Hence the cloud droplet number concentration was thought to be positively related to cloud albedo and the cloud column susceptibility could not be negative. However, the inverse relation between droplet size and optical thickness is implicitly based on the assumption of constant liquid water content, which is not supported by most observations. If this assumption is not used, then because

$$
w=k r_{e}^{3} \rho_{w} N
$$

where $k=4 \pi(1-b)(1-2 b)$ and $b$ ranges from 0.10 to 0.20 (Han et al. 1994), we have

$$
\tau=\frac{3}{2} \frac{w}{r_{e}} h=\frac{3}{2} k r_{e}^{2} \rho_{w} N_{c}
$$

Instead of an inverse relationship between $\tau$ and $\mathrm{r}_{e}$, we may have $\tau$ and $\mathrm{r}_{e}$ positively correlated if $N_{c}$ is close to constant as indicated by some observations (Lohmann et al., 2000). In fact, observations show that a decrease of cloud droplet size is linked with a decrease of the optical thickness for most clouds on the earth (Han et al., 1998a). In the study of cloud-aerosol interactions, cloud droplet number concentration is apparently changing and neither $\Delta w=0$ nor $\Delta N_{c}=0$ should be used. From 
equation (7), the change of $\tau$ (hence the change of the cloud albedo, $\alpha$ ) due to changes in $N_{c}$ can be written as

$$
\Delta \tau / \Delta N_{c}=3 k \rho_{w} r_{e} N_{c}\left[\frac{r_{e}}{2 N_{c}}+\frac{\Delta r_{e}}{\Delta N_{c}}\right]
$$

which makes cloud susceptibility negative if $\Delta r_{e} / \Delta N<-0.5 r_{e} / N$. This condition means, by comparison with equation (6), a decrease of cloud liquid water content in the cloud-aerosol interactions.

Figure 3 is an example of positive column susceptibility from NOAA-9 data in January 1987 (located at the south of Australia). In the figure, increasing of cloud albedo is roughly determined by increases of the optical thickness. For example, albedo $(\alpha)$ variation between 0.15 to 0.20 corresponds to optical thickness $(\tau)$ change between 1.3 to $1.9, \alpha$ between 0.20 to 0.25 corresponds to $\tau$ between 1.4 to 3.0 , $\alpha$ between 0.25 to 0.30 corresponds to $\tau$ between 3.0 to 3.9 , and $\alpha$ between 0.30 to 0.35 corresponds to $\tau$ between 3.6 to 4.9 . Within a small interval of optical thickness, droplet sizes become smaller when the column number concentration increases, this is readily understood from equation (10). Figure 3 shows that in this region, the column number concentrations of most thin clouds are less than $2.0 \times 10^{6} \mathrm{~cm}^{-2}$ while most thick clouds are between 1.5 to $3.0 \times 10^{6} \mathrm{~cm}^{-2}$, which makes the column susceptibility positive. A comparison between two different approaches is also shown in the Fig. 3 with the column susceptibility values retrieved by approach one shown in different symbols. The unit of the column susceptibility $\left(\mathrm{S}_{c}\right)$ in the figure is $10^{-8} \mathrm{~cm}^{2}$. It is readily seen that the column susceptibility by approach one is strongly dependent on the value of $N_{c}$, which is understandable because the range of $\Delta N_{c}$ is much larger than the range of $\Delta[\alpha(1-\alpha)]$ in the equation (5). The average column susceptibility of all pixels from approach one is $6.1 \times 10^{-8} \mathrm{~cm}^{2}$, larger than the result of $5.1 \times 10^{-8} \mathrm{~cm}^{2}$ by the regression method. In other grid boxes, we have seen much larger differences between results from these two approaches. This comparison suggests that holding liquid water content constant may overestimate the indirect aerosol effects.

Figure 4 shows an example of negative column susceptibility of January 1987 (located at the west coast of Peru). The averaged column susceptibility using approach one is $3.2 \times 10^{-8} \mathrm{~cm}^{2}$, 
while the result of approach two yields $S_{c}=-0.63 \times 10^{-8} \mathrm{~cm}^{2}$. In comparison with Fig. 3, column number concentration is larger and droplet size is smaller for all optical thickness levels. This is a result not expected by holding liquid water content constant, which would predict larger column number concentration and smaller droplet size only for larger optical thickness. An explanation is that when more $\mathrm{CCN}$ becomes cloud droplets and cloud droplet size population shifts to smaller values, the evaporation rate is stronger because of the curvature effect. This stronger evaporation "burns" out cloud liquid water content and prevents cloud uptical thickness from increasing, which can be seen from equation (10) as the increase of number concentration cancels out the decrease of droplet radius.

\section{Discussion and Conclusions}

In order to reduce the uncertainty in evaluation of aerosol indirect effect, it is necessary to combine model study, in situ measurements and satellite measurements to improve our understanding of the cloud-aerosol interactions (NRC, 1996). In recent years, prognostic scheme of liquid water content has been used in GCMs (e.g., Easter et al., 1999, Lohmann et al. 1999). The results of these models show promising agreement with satellite observations on cloud droplet size, cloud column droplet concentration, and the relationship between cloud albedo and droplet sizes (Ghan et al., 1999, Lohmann et al., 1999). These progresses are important not only for evaluation of the aerosol indirect effect but also for assessment of the cloud feedback mechanisms. Apparently, we need more comparisons between observations and model studies to improve our understanding of the key processes involving the aerosol indirect effect.

A new parameter, cloud column susceptibility, is introduced in this study which can be retrieved using satellite data and can be used to compare with product of model studies. Two different approaches, with and without assumption of constant liquid water content in the cloudaerosol interaction, were used to retrieve the cloud column susceptibility using ISCCP data. The results from both approaches show continental-maritime contrast that is consistent with differences of aerosol loading over these two surfaces. However, values of cloud column susceptibility 
retrieved from no assumption of constant liquid water content are generally smaller than that from another approach. They can even become negative at some regions, a result that is not possible if liquid water content is held constant. This finding suggests that using constant liquid water content in the model may overestimate the aerosol indirect effect and that the new development of the prognostic cloud water schemes in GCMs may yield more realistic evaluations.

The cloud column susceptibility itself, without the knowledge of droplet size change and the droplet size effect on albedo, can be regarded as a description of the aerosol indirect effect. To this end, this study shows that the current aerosol indirect effect is largest over remote ocean areas (cf. Fig 2). As pollution increases, the aerosol indirect effect may become less and even saturated that is evidenced by the small (sometimes negative) values of cloud column susceptibility over most continents and surrounding areas.

Acknowledgments. This research was supported by NASA grant No. NAG5-7702, NCC8141 and NAG1-1955.

\section{References}

Easter, R. C., S. J. Ghan, R. D. Saylor, E. G. Chapman, H. Abdul-Razzak, L. R. Leung, Y. Zhang, X. Bian, and R. A. Zaveri, 1999: MIRAGE: A model for integrated research on atmospheric global exhanges. [submitted to J. Geophys. Res., ]

Fitzgerald, J. W., and P. A. Spyers-Duran, 1973: Changes in cloud nucleus concentration and cloud droplet size distribution associated with pollution from St. Louis. J. Appl. Meteor., 12, 511-516.

Ghan, S., R. Easter, J. Hudson, and F. M. Breon, 1999: Evaluation of aerosol indirect radiative forcing in MIRAGE. [Submitted to J. Geophys. Res.,]

Han, Q., W. B. Rossow, and A. A. Lacis, 1994: Near-global survey of effective droplet radii in liquid water clouds using ISCCP data. J. Climate, 7, 465-497.

Han, Q., W. B. Rossow, J. Chou, and R. M. Welch, 1998a: Global survey of the relationship of cloud albedo and liquid water path with droplet size using ISCCP. J. Climate, 11, 1516-1528. 
Han, Q., W. B. Rossow, J. Chou, and R. M. Welch, 1998b: Global Variation of Droplet Column Concentration of Low-level Clouds. J. Geophys. Letts., 25, 1419-1422.

Hobbs, P. V., L. F. Radke, and S. E.Shumway, 1970: Cloud condensation nuclei from industrial sources and their apparent influence on precipitation in Washington State. J. Atmos. Sci., 27, 8189.

Leaitch, W. R., G. A. Isaac, J. W. Strapp, C. M. Banic, and H. A. Wiebe, 1992: The relationship between cloud droplet number concentrations and anthropogenic pollution: Obsirvations and climatic implications. J. Geophys. Res., 97, 2463-2474.

National Research Council, 1996: A Plan for a Research Program on Aerosol Radiative Forcing and Climate Change. National Academy Press, Washington, D. C. 161 pp.

Platnick, S., and S. Twomey, 1994: Determining the susceptibility of cloud albedo to changes in droplet concentration with the Advanced Very High Resolution Radiometer. J. Appl. Meteor., 33, 334-347.

Pruppacher, H. R., and J. D. Klett, 1997: Microphysics of clouds and precipitation. $2^{\text {nd }}$ Edition, Kluwer Academic Publishers, 954pp.

Radke, L. F., an J. A. Coakley, Jr., M. D. King, 1989: Direct and remote sensing observations of the effects of ships on clouds. Science, 246, 1146-1149.

Rossow, W. B., and R. A. Schiffer, 1991: ISCCP cloud data products. Bull. Amer. Meteor. Soc. 72, 2-20.

Taylor, J. P., and A. McHaffie, 1994: Measurements of cloud susceptibility. J. Atmos. Sci., 51, 1298-1306.

Twomey, S., 1991: Aerosols, clouds and radiation. Atmospheric Environment, 25A, 2435-2442. 

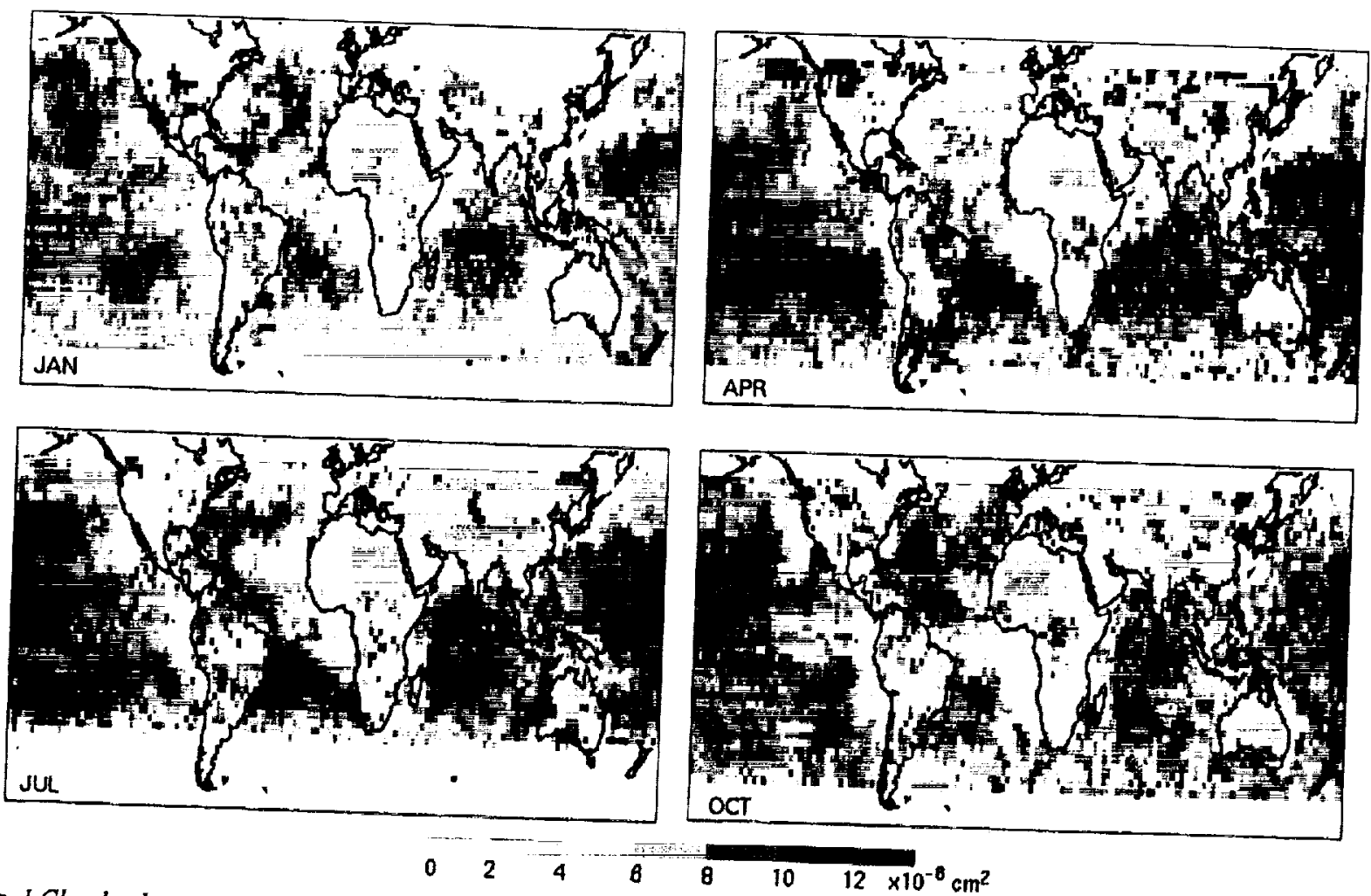

Fig. I Cloud column susceptibility retrieved from NOAA-9 data of 1997 under the assumption of constant liquid water content
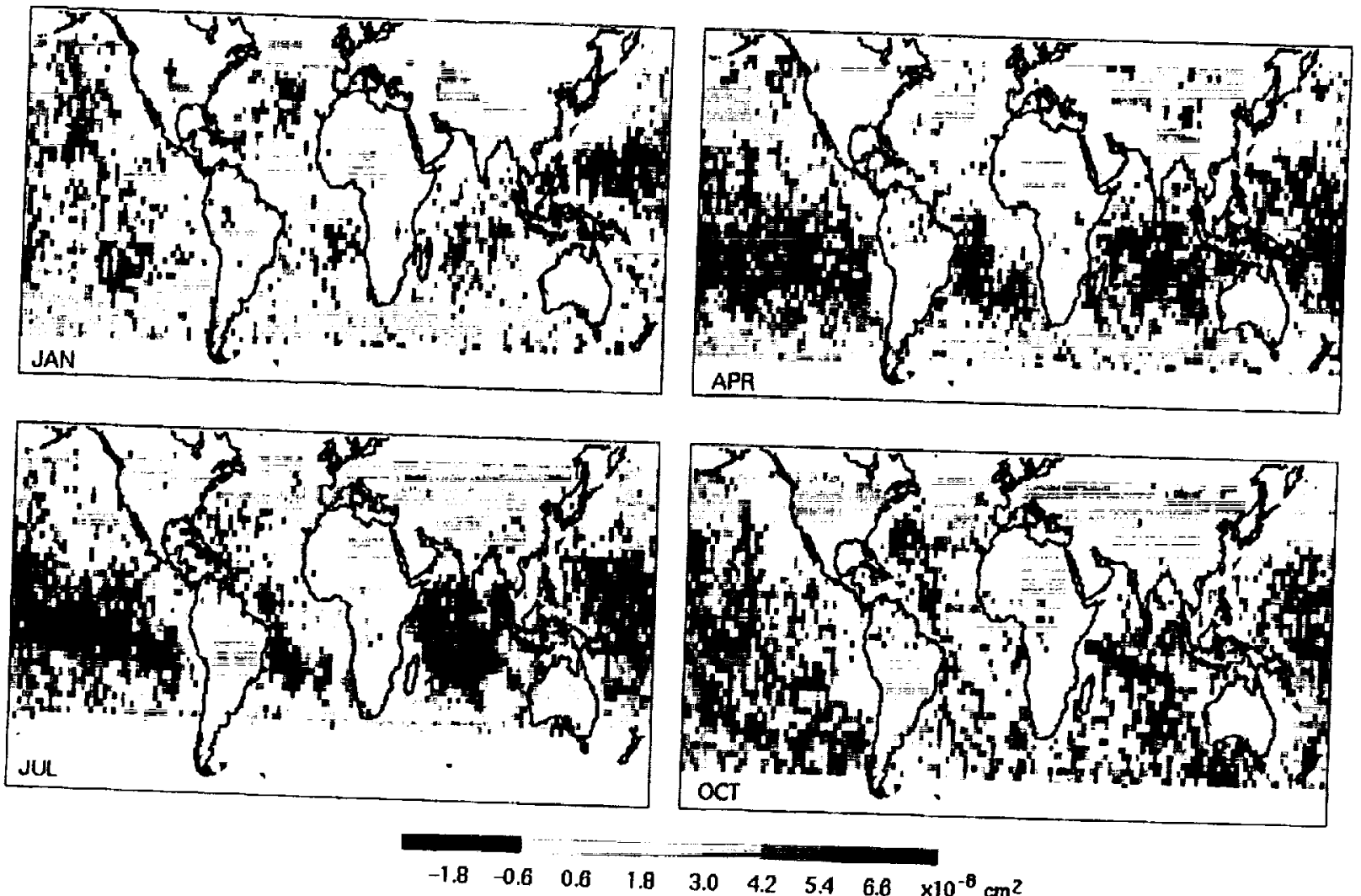

Fig. 2 Same as in Fig. 1 but with no assumption about constant liquid water content 

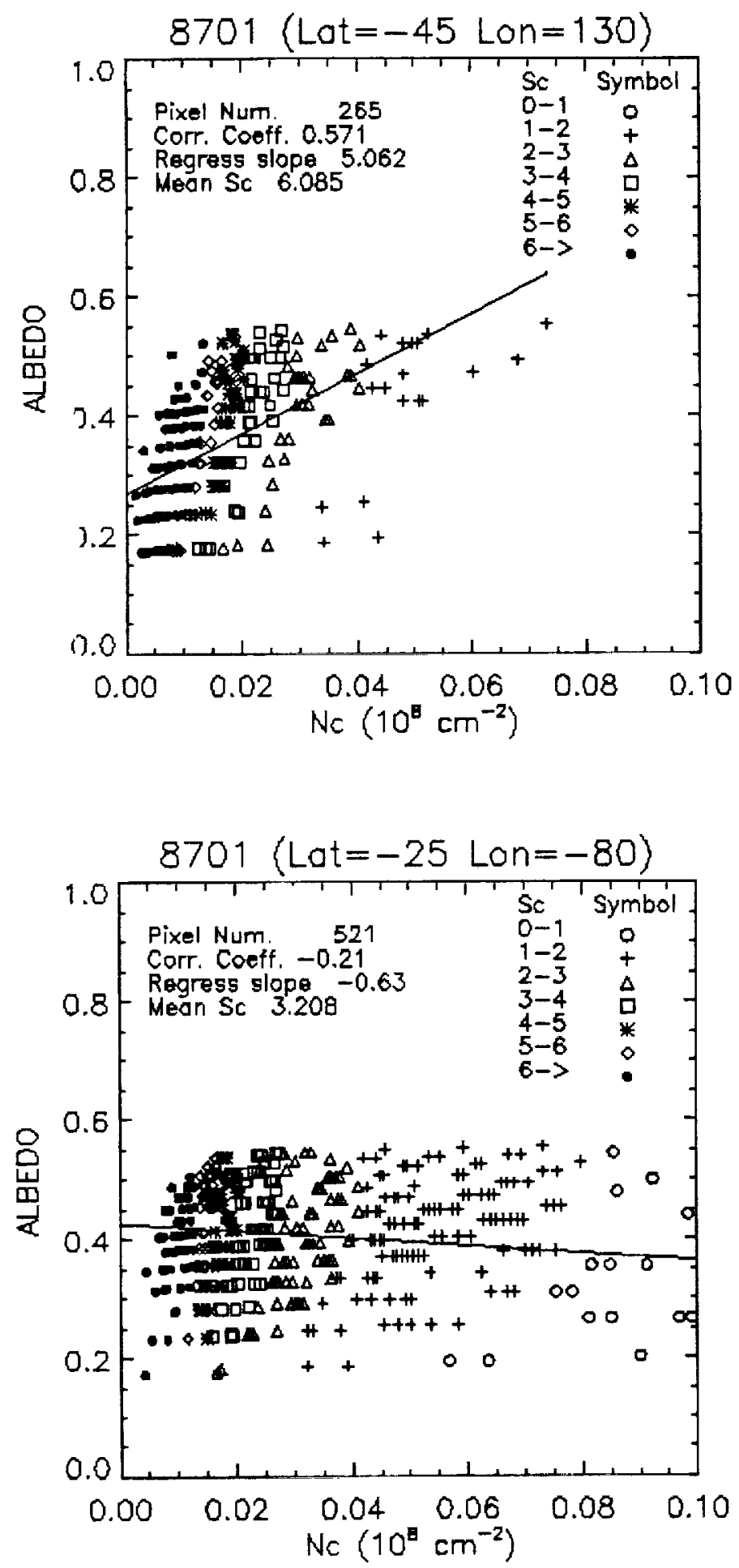

Figure 3 Example of positive column susceptibility within a grid box at south of Australia
Figure 4 Example of negative column susceptibility within a grid box at the west coast of Peru. 